\title{
Enhanced excitability of the uterus of the pregnant rabbit by imidazole stimulation of cyclic AMP phosphodiesterase
}

\author{
W. B. Currie \\ Department of Animal Science, Cornell University, Ithaca, New York 14850, U.S.A.
}

\begin{abstract}
Summary. Imidazole, at concentrations between $10^{-3}$ and $10^{-2} \mathrm{M}$, exerts a profound stimulatory effect on rabbit uterine strips obtained during pregnancy and studied isometrically in vitro. The action is not duplicated by $N$-alkylimidazoles which have greater potency as inhibitors of thromboxane synthetase but the effect of imidazole was antagonized by isoproterenol or theophylline. Biochemical analysis indicated that imidazole at concentrations greater than $5 \times 10^{-4} \mathrm{M}$ stimulated both high and low affinity forms of cyclic AMP phosphodiesterase. The uterus of pregnant rabbits is profoundly refractory to any kind of pharmacological stimulation and the effects of imidazole, acting to stimulate phosphodiesterase, suggest that the integrity of the adenyl cyclase-cyclic AMP-protein kinase system is a necessary requirement for this organ to remain quiescent during pregnancy.
\end{abstract}

\section{Introduction}

During pregnancy the rabbit uterus is remarkedly refractory to pharmacological stimulation and generates virtually no spontaneous activity either in situ or in vitro until shortly before term. Csapo (1977) has demonstrated that the functional behaviour of the pregnant rabbit uterus reflects its inexcitability, a consequence of the progesterone-influenced sarcolemma. Numerous possible mechanisms could mediate the progesterone effect, e.g. hyperpolarization of the membrane, insufficient numbers of receptors to agonists, impaired electrocoupling of cells reflecting inadequate numbers of gap junctions and excessive sarcolemmal capacity to sequester activator- $\mathrm{Ca}^{2+}$. We have recently demonstrated in tissue culture experiments that the resistance of rabbit uterus to the uncoupling of excitation and contraction by $\mathrm{Ca}^{2+}$-free solutions can be manipulated by progesterone treatments in vitro (Currie \& Jeremy, 1979). Resistance to uncoupling could be altered reversibly over a time-course of a few hours and the effect of progesterone was mimicked by inhibitors of protein synthesis. Currie (1979) suggested that components of the sarcolemma capable of sequestering activator- $\mathrm{Ca}^{2+}$ were present under the influence of progesterone and that these were lost when the suppression of certain transcriptional events by progesterone was removed.

As in other smooth muscle systems, $\beta$-adrenomimetic drugs suppress uterine contractile activity by elevating cAMP concentrations, activation of protein kinases, phosphorylation of membrane holoproteins and enhanced membrane binding of $\mathrm{Ca}^{2+}$ (Krall, Schindler \& Korenman, 1978). Although it remains to be established whether the membrane substrates for protein kinase are the components whose turnover is regulated by progesterone, it seemed possible that a suppression of phosphorylation might unmask an inherent excitability in the otherwise quiescent rabbit uterus under the progesterone influence of pregnancy. To explore this possibility, imidazole, a stimulator of cAMP phosphodiesterase, was used to interrupt the sequence controlling phosphorylation to test if contractions could be elicited in uterine strips from pregnant rabbits. 


\section{Materials and Methods}

Primiparous New Zealand White rabbits weighing 3.5-4.5 kg were used at known days of pregnancy (mated Day 0). The animals were killed by stunning and exsanguination and the uterus was rapidly excised, opened lengthwise, emptied and placed immediately in KrebsRinger-bicarbonate (KRB) solution gassed with $95 \% \mathrm{O}_{2}: 5 \% \mathrm{CO}_{2}$ to $\mathrm{pH} 7 \cdot 35-7 \cdot 4$. The solution consisted of (in $\mathrm{mM}$ ): $\mathrm{NaCl}, 118.6 ; \mathrm{KCl}, 4.75 ; \mathrm{CaCl}_{2}, 2.54 ; \mathrm{KH}_{2} \mathrm{PO}_{4}, 1.19 ; \mathrm{MgSO}_{4}$, $1 \cdot 19, \mathrm{NaHCO}_{3}, 2.46$ and glucose, 5.56. After removing fat, gross connective tissue and placental remnants, uniform longitudinal strips $(30 \times 4 \mathrm{~mm} \times$ natural thickness) were cut from the antimesometrial surface and mounted isometrically in KRB at $2 \mathrm{~g}$ resting tension in the apparatus described by Csapo (1976). The strips were repeatedly tetanized for $4 \mathrm{sec}$ every 30 sec by a longitudinal electric field $(60 \mathrm{~Hz}$ a.c., $2.4 \mathrm{~V} / \mathrm{cm}$ ) established between 2 platinum ring electrodes under the control of a microprocessor-regulated relay. The active tension was measured with Grass FT 0.03 force displacement transducers and displayed on a Grass 7D polygraph. When active tension reached a high level steady state $(5-7 \mathrm{~min})$, electrical stimulation was discontinued and the bathing fluid was exchanged for fresh $\mathrm{KRB}$ at $37^{\circ} \mathrm{C}$. Drug additions (in KRB) were made at this time and any resultant contractile activity was recorded. Imidazole at $10^{-2} \mathrm{M}$ was adjusted to $\mathrm{pH} 7.4$ with $\mathrm{HCl}$; other additions were adequately buffered by the KRB.

For biochemical studies, trimmed uterine wall was freed of endometrium by gentle scraping then the myometrium was dissected from the ligament, finely minced then digested for $60 \mathrm{~min}$ at $37^{\circ} \mathrm{C}$ in KRB containing $1 \mathrm{mg}$ collagenase $/ \mathrm{ml}$. The digest was filtered twice over 2 layers of cheesecloth and the cells pelleted at $250 \mathrm{~g}$ for $15 \mathrm{~min}$. The pellet was dispersed in 40 mM-Tris- $\mathrm{HCl}(\mathrm{pH} 8.1)$ containing $10 \mathrm{mM}-\mathrm{MgCl}_{2}$ and $2 \mathrm{~mm}$-dithiothreitol and homogenized in a Dounce apparatus using 20 strokes with the tight (A) pestle. A total particulate fraction was separated from the cytosol by centrifuging at $100000 \mathrm{~g}$ for $60 \mathrm{~min}$. The pellet was dispersed in the same buffer in a Polytron before analysis.

The assay of Rangel-Aldao, Schwartz \& Rubin (1978) for cyclic AMP-phosphodiesterase (EC 3.1.4.17) was modified to enable use of microvolumes and economy of tritiated substrate. Assay tubes (500 $\mu$ l Eppendorf polypropylene centrifuge tubes) containing $40 \mathrm{nM}-\left[{ }^{3} \mathrm{H}\right]$ adenosine $3^{\prime}, 5^{\prime}$-phosphate, $0-300 \mu \mathrm{M}$ non-radioactive cAMP, 0-10 mM-imidazole- $\mathrm{HCl}$ and 1-12 $\mu \mathrm{g}$ protein in a total volume of $15 \mu \mathrm{l}$ of the Tris- $\mathrm{HCl}(\mathrm{pH} \mathrm{8.1)}$ buffer. Reactions were started by adding the enzyme source and mixing. After 5 or $10 \mathrm{~min}$ at $37^{\circ} \mathrm{C}$, reactions were quenched by adding $5 \mu \mathrm{l}$ of a cocktail of adenosine, inosine, adenosine $5^{\prime}$-monophosphate and cAMP (each $12.5 \mathrm{~mm}$ ) and the mixed tubes were placed in melting ice. Twelve aliquots of the reaction mixes were streaked on polyethyleneimine-cellulose plates $(20 \times 10 \mathrm{~cm})$, dried then developed in 50 mM-aqueous $\mathrm{KCl}$ to a height of $7 \mathrm{~cm}$. Dried chromatograms were examined under u.v. light and bands corresponding to substrate and products were marked. The plates were cut into scintillation vials, shaken with $10 \mathrm{ml}$ toluene-Omnifluor and counted in a Packard 2450 Liquid Scintillation Spectrometer. Radioactivity associated with each product was corrected for the fractional hydrolysis observed in substrate blanks (less than $0.05 \%$ per min) then used to calculate total hydrolysis in each assay tube. All unknown samples were pretested and diluted to provide about $1 \%$ hydrolysis of the ${ }^{3} \mathrm{H}$-labelled substrate (no non-radioactive cAMP) per min. There was a wide margin for linearity of percentage hydrolysis, with respect to both protein concentration and time, provided total hydrolysis was less than $25 \%$, around the values chosen for testing.

The activity of $5^{\prime}$-nucleotidase (EC 3.1.3.5) was assayed at $\mathrm{pH} 7.0$ using $5 \mathrm{~mm}$-adenosine 5 '-monophosphate. At higher $\mathrm{pH}$ values, rabbit uterine preparations display excessive non-specific phosphohydrolysis and even at $\mathrm{pH} 7.0$ it is critical to adjust for hydrolysis of $2^{\prime}$-adenosine monophosphate or $\beta$-glycerophosphate. Assays were performed over $10 \mathrm{~min}$ at $37^{\circ} \mathrm{C}$ by adding $100-300 \mu \mathrm{g}$ protein to $5 \mathrm{~mm}$ solutions of $5^{\prime}$ - AMP (and blank tubes containing 
$5 \mathrm{mM}-2^{\prime}$-AMP or $\beta$-GP) in $25 \mathrm{mM}$-Tris- $\mathrm{HCl}\left(\mathrm{pH} 7.0\right.$ ) containing $5 \mathrm{mM}-\mathrm{MgCl}_{2}$ and $10 \mu \mathrm{M}$ sodium potassium tartrate. After precipitating proteins with an equal volume of $10 \%(\mathrm{w} / \mathrm{v})$ trichloroacetic acid, inorganic phosphate in the supernatants was measured by the method of Chen, Toribara \& Warner (1956).

Samples were hydrolysed at $100^{\circ} \mathrm{C}$ for $60 \mathrm{~min}$ in $0.1 \mathrm{~N}-\mathrm{NaOH}$ containing $0.1 \%(\mathrm{w} / \mathrm{v})$ sodium dodecyl sulphate and protein was measured by the method of Lowry, Rosebrough, Farr \& Randall (1951) using crystalline bovine serum albumin in $\mathrm{NaOH} / \mathrm{SDS}$ as standards.

5'-AMP, 2'-AMP, $\beta$-glycerophosphate, cAMP, adenosine, inosine, theophylline, isoproterenol and Type IV collagenase were obtained from Sigma, St Louis, Missouri; SDS was electrophoresis grade from Biorad, Richmond, California; tritiated cAMP and Omnifluor were from New England Nuclear, Boston, Massachusetts; PEI-Cellulose plates were from Merck (MC/B Manufacturing Chemists, Cincinnati, Ohio). $N$-Substituted imidazoles were prepared and kindly provided by Dr C. F. Wilkinson, Cornell University.

\section{Results}

In striking contrast to the complete absence of contractions in control uterine strips after discontinuing electric field stimulation, addition of 1-10 mM-imidazole provoked regular, cyclic contractions of high amplitude. The latency before contractions started was inversely related to the final concentration of imidazole (Text-fig. 1) but the level of active tension developed was unrelated to dose and was quite comparable to that elicited by optimal electric driving. At the highest dose employed, excitability was increased to such a degree that a transient contraction was observed before regular phasic contractions with complete relaxations were established. In one test, these cyclic contractions were sustained for at least $3 \mathrm{~h}$ without further treatment.

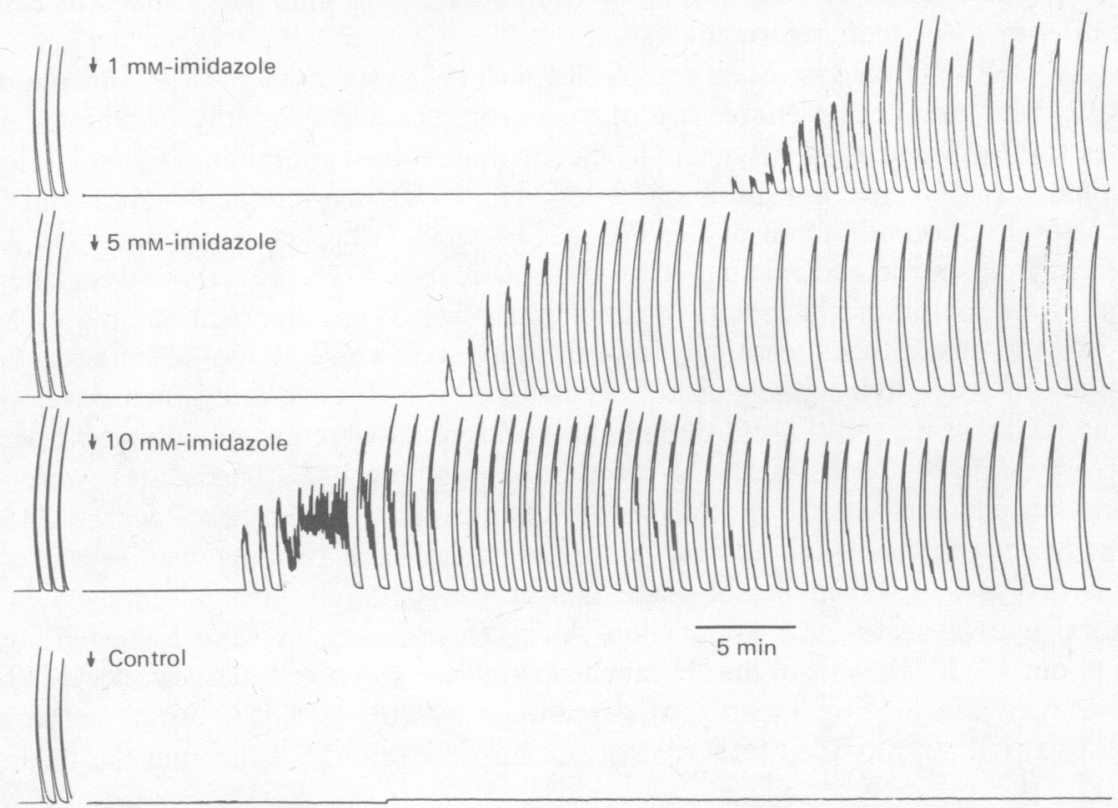

Text-fig. 1. Effect of imidazole on pregnant rabbit uterus in vitro. Uterine strips from a rabbit on Day 24 of pregnancy were tetanized until full active tension was developed. Three electrically driven contractions were recorded, then the bathing medium was changed as indicated to include $0-10^{-2} \mathrm{M}$ imidazole in Krebs-Ringer-bicarbonate. Recording continued for $50 \mathrm{~min}$ without further electrical stimulation. Full-scale deflection for each tracing is $50 \mathrm{~g}$. 
In preliminary studies, three $N$-alkylated imidazole derivatives ( $N$-butylimidazole, $N$ nonylimidazole and $N$-phenylimidazole) were quite ineffective in provoking contractions when tested at $1 \mathrm{~mm}$ concentrations. Higher concentrations could not be tested because of the limited solubility of these oils in KRB at pH 7.4. The effects of imidazole (Text-fig. 1) were antagonized in a dose-related fashion by simultaneous addition of $10^{-6}-10^{-3} \mathrm{M}-l$-isoproterenol, a potent $\beta$-agonist, or by $10^{-5}-10^{-2} \mathrm{M}$-theophylline, a phosphodiesterase inhibitor (tracings not shown).

Since the agonist effect of imidazole shown here is quite remarkable in view of the pronounced refractoriness of the pregnant rabbit uterus to pharmacological stimulation, it seemed possible that information on its mechanism of action could be valuable for gaining better understanding of the regulation of uterine excitability in this species.

Approximately $72 \%$ of the cAMP phosphodiesterase activity was soluble. Both the high and low $K_{\mathrm{m}}$ forms of the enzyme were distributed in this way between the particulate and soluble biophases of rabbit myometrium. Only $31 \%$ of the protein was soluble so specific activity of phosphodiesterase expressed per unit of protein was some 6-fold higher in the soluble fraction. In contrast, virtually all (96\%) 5 '-nucleotidase activity was recovered in the particulate fraction, indicating the mildness of the cell disrupting procedure used because this enzyme is readily solubilized from its sarcolemmal location during tissue homogenization.

The cAMP phosphodiesterase clearly exists in at least two forms as determined by Lineweaver-Burk analysis. The high affinity form $\left(K_{\mathrm{m}}=3.8 \times 10^{-6} \mathrm{M}\right)$ is presumed to be of greater significance in degrading intracellular cAMP at the $\mu \mathrm{M}$ concentrations normally measured in myometrium.

The effect of imidazole on the double reciprocal plot of soluble cAMP phosphodiesterase activity is shown in Text-fig. 2. At $10^{-2} \mathrm{M}$ concentrations, imidazole increased $V_{\max }$ by about $50 \%$ despite a slight increase in the $K_{\mathrm{m}}$ of the higher affinity form. A similar effect was observed on the particulate enzyme source.

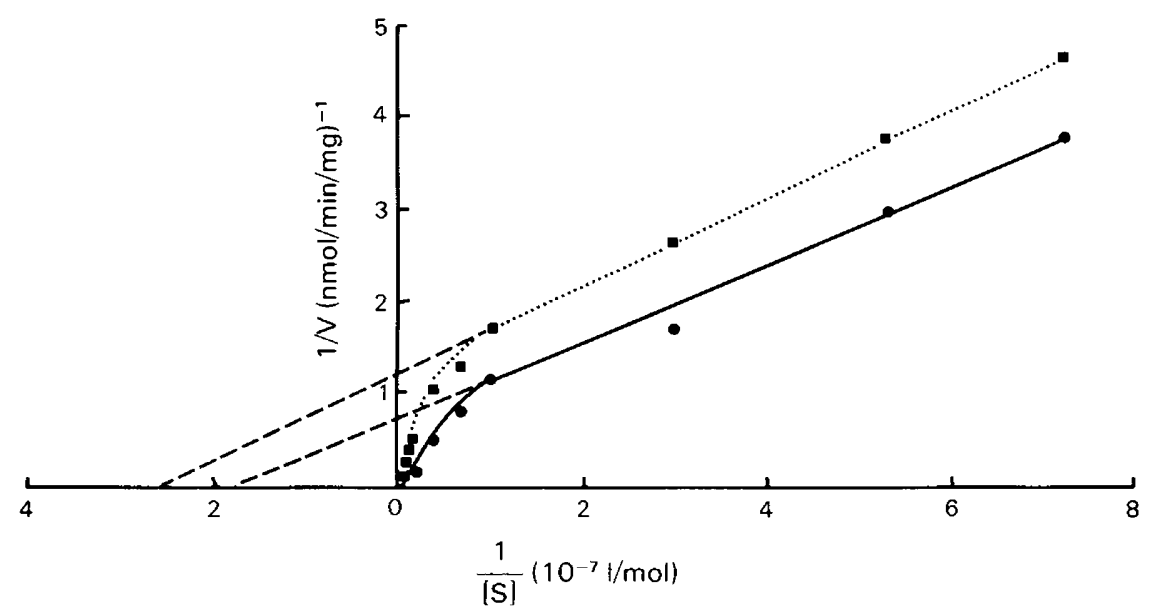

Text-fig. 2. Effect of imidazole on cAMP-phosphodiesterase in the cytosol of rabbit myometrium at Day 23 of pregnancy. A Lineweaver-Burk plot for substrate concentrations between $0.4 \times 10^{-6} \mathrm{M}$ and $0.3 \times 10^{-3} \mathrm{M}$ indicates the presence of high and low affinity forms of the enzyme. Extrapolation of the high affinity data points indicates a $V_{\max }$ and $K_{\mathrm{m}}$ of 800 $\mathrm{pmol} / \mathrm{min} / \mathrm{mg}$ and $3.77 \times 10^{-6} \mathrm{M}$ respectively for controls $(\ldots \ldots)$ and $1250 \mathrm{pmol} / \mathrm{min} / \mathrm{mg}$ and $5.26 \times 10^{-6} \mathrm{M}$ in the presence of $10^{-2} \mathrm{M}$ imidazole $(-)$.

Further analyses were made using substrate concentrations appropriate for each of two forms of the enzyme $\left(0.4 \times 10^{-6} \mathrm{M}\right.$ and $0.3 \times 10^{-3} \mathrm{M}$ for the high and low affinity forms, respectively). Concentrations of imidazole greater than $5 \times 10^{-4} \mathrm{M}$ stimulated both forms and 
both sources; maximal stimulation was obtained with $10^{-2} \mathrm{M}$ imidazole. Under the assay conditions used (Table 1), imidazole stimulated the high affinity enzyme by $26 \%$. At higher substrate concentrations, the soluble enzyme was stimulated by $32 \%$ but a disparate effect ( $154 \%$ stimulation) was noted on all particulate fractions tested. At $10^{-3} \mathrm{M}$ concentrations, the $N$-alkylated imidazoles and $l$-isoproterenol were without effect on the high and low affinity forms of the enzyme, while theophylline at concentrations greater than $10^{-5} \mathrm{M}$ reduced \% hydrolysis of cAMP $\left(0.4 \times 10^{-6} \mathrm{M}\right)$, eventually at $10^{-2} \mathrm{M}$ concentrations to the level of the blanks. Theophylline at these concentrations also reversed the stimulation by $10^{-2} \mathrm{M}$-imidazole. Neither these compounds nor imidazole itself had any apparent effect on $5^{\prime}$-nucleotidase activity in the myometrial preparations. However, during $5^{\prime}$-nucleotidase assays non-specific phosphohydrolysis by particulate myometrial fractions was stimulated by $10^{-2} \mathrm{M}$-imidazole, and this might account for the excessive stimulation of the low affinity form of phosphodiesterase.

Table 1. Stimulation by imidazole of cAMP-phosphodiesterases ( $\mathrm{pmol} / \mathrm{min} / \mathrm{mg}$ protein) in pregnant rabbit myometrium

\begin{tabular}{lccccc}
\hline & \multicolumn{2}{c}{ High affinity } & & \multicolumn{2}{c}{ Low affinity } \\
& \multicolumn{2}{c}{$[\mathrm{S}]=0.4 \times 10^{-6} \mathrm{M}$} & & \multicolumn{2}{c}{$[\mathrm{S}]=0.3 \times 10^{-3} \mathrm{M}$} \\
\cline { 2 - 3 } \cline { 6 - 7 } & Cytosol & Particulate & & Cytosol & Particulate \\
\hline Control & $69.4 \pm 0.7$ & $12.2 \pm 0.4$ & & $3282 \pm 178$ & $1423 \pm 29$ \\
Imidazole* & $87.4 \pm 1.7$ & $16.4 \pm 0.9$ & & $4868 \pm 407$ & $3615 \pm 65$ \\
\% Stimulation & 26 & 26 & & 32 & 154 \\
\hline
\end{tabular}

Values are mean \pm s.e.m. for 4 observations.

* $10^{-2} \mathrm{M}$, buffered to $\mathrm{pH} 8 \cdot 1$ with $\mathrm{HCl}$.

\section{Discussion}

The finding that imidazole was capable of initiating advanced high level cyclic contractions in uterine strips of pregnant rabbits is of considerable interest because this tissue is normally quiescent and refractory to even massive stimulation with agonists such as oxytocin and prostaglandin F-2 $\alpha$. The pharmacological properties of imidazole include inhibition of haem-containing, mixed-function oxidases in microsomes (Wilkinson, Hetnarski, Cantwell \& DiCarlo, 1974), stimulation of cAMP phosphodiesterase and inhibition of thromboxane synthetase (Needleman, Raz, Ferrendelli \& Minkes, 1977). This last property may be of importance in myometrium in which prostaglandin metabolism is a central factor in the control of contractile activity. Thromboxane synthesis is inhibited by $N$-nonylimidazole with a potency of about 1000 -fold relative to imidazole (Tai \& Yuan, 1978) but this substituted imidazole, and selected analogues that would be expected to gain ready access to the cytoplasm, were unable to mimic the uterotonic effect seen here for imidazole itself. Further pharmacological testing indicated that the response to imidazole was antagonized by $l$-isoproterenol or by theophylline, drugs that would be expected to elevate intracellular concentrations of cAMP. Thus, in attempts to account for imidazole's mechanism of action in this system, interest centred on the observations (Ferre, DePariente, Breuiller \& Cedard, 1978) that this heterocyclic base can stimulate the activity of cAMP phosphodiesterase.

Two methodological aspects that emerged from the present work deserve mention. Phosphodiesterase activity (both high and low affinity forms) was present in both the cytosol and particulate fractions prepared from rabbit myometrium. The low affinity phosphodiesterase I has been used as a sarcolemmal marker enzyme in the rat (Kidwai, Radcliffe \& Daniel, 1971); it is unlikely to be suitable for monitoring fractionation of rabbit myometrial organelles. In contrast, 5'-nucleotidase activity, when adjusted for the problematic non-specific 
phosphohydrolysis, was virtually confined to the particulate fraction. With crude fractions such as those used here, non-specific hydrolysis may account for $80 \%$ of total measured phosphohydrolysis. Studies in progress confirm that this enzyme is a very suitable marker of the sarcolemma in rabbit myometrium and its specific activity has been enriched 35 -fold during isolation of sarcolemmal preparations (W. B. Currie, unpublished results).

It has been argued that the intracellular concentration of cAMP is a critical determinant of whether a smooth muscle cell contracts or is relaxed (Korenman \& Krall, 1977). Thus, factors capable of reducing cAMP concentrations would be expected to promote contractile activity. In this study, cAMP phosphodiesterase activity in broken cell preparations was increased by concentrations of imidazole that were effective in eliciting cyclic contractile activity in uterine strips prepared from rabbits in a similar physiological state.

As a result of numerous experimental studies, Csapo (1977) has concluded that the characteristic inactivity and pharmacological refractoriness of the pregnant rabbit's uterus is a reflection of the influence of progesterone on the properties of the myometrial sarcolemma. He has proposed that the inexcitability of the progesterone-influenced myometrial cell results from (or is associated with) the capacity of the sarcolemma to bind $\mathrm{Ca}^{2+}$. Our recent evidence showing that this progesterone effect can be established in vitro (Currie \& Jeremy, 1979) and can be mimicked by cycloheximide or actinomycin D (Currie, 1979) has been interpreted to indicate that progesterone might be controlling sarcolemmal properties by tonically inhibiting synthesis of protein(s) concerned with the turnover of $\mathrm{Ca}^{2+}$ binding sites. However, it is possible that the sarcolemmal components subject to control on a more chronic timescale by progesterone serve as substrates for phosphorylation by cAMP-dependent protein kinases (Krall et al., 1978) which provide a more acute or sensitive regulation of $\mathrm{Ca}^{2+}$ binding.

The present study has shown that disruption of the cAMP regulated control by stimulating cAMP phosphodiesterase results in a breakthrough of contractions despite the progesterone influence. It therefore seems very likely that the progesterone influence on myometrial excitability is only expressed when an adequate level of cAMP-regulated control is provided. The possibility that the suppression of uterine excitability by progesterone and the adenylate cyclase-cAMP system are physiologically complementary during pregnancy is presently being explored further using purified sarcolemma from the myometrium of pregnant rabbits.

This study was supported in part by a PHS grant HD 13458 from the National Institute of Child Health and Human Development, NIH, Bethesda, MD. Funding for the polygraph was in part from a PHS Biomedical Research Support Grant to Cornell University. I thank Dr C. F. Wilkinson for the $\mathrm{N}$-alkylated imidazoles; Jamie Jeremy and Joseph Cioffi for technical assistance and Marion Stevens for secretarial help.

\section{References}

Chen, P.S., Toribara, T.Y. \& Warner, H. (1956) Microdetermination of phosphorous. Analyt. Chem. 28, 1756-1758.

Csapo, A.I. (1976) Effects of progesterone, prostaglandin $\mathrm{F}_{2 a}$ and its analogue ICI 81009 on the excitability and threshold of the uterus. Am. J. Obstet. Gynec. 124, 376-378.

Csapo, A.I. (1977) The 'see-saw' theory of parturition. Ciba Found. Symp. 47, 159-195.

Currie, W.B. (1979) Uterine excitability and distensibility influenced by treatment in vitro with progesterone. Anim. Reprod. Sci. 2, 225-238.

Currie, W.B. \& Jeremy, J.Y. (1979) In vitro action of progesterone on myometrium. 1. Reversible modulation of the resistance of rabbit uterus to excitation-contraction uncoupling. Biol. Reprod. 21 , 945-952.

Ferre, F., DePariente, D., Breuiller, M. \& Cedard, L. (1978) Inhibition of human myometrial cyclic AMP phosphodiesterase by uterine relaxant drugs. Biochem. Pharmacol. 27, 1292-1294.

Kidwai, A.M., Radeliffe, M.A. \& Daniel, E.E. (1971) Studies on smooth muscle plasma membrane. I. Isolation and characterization of plasma membrane from rat myometrium. Biochem. Biophys. Acta 233, 538-549.

Downloaded from Bioscientifica.com at 04/26/2023 03:38:01AM 
Korenman, S.G. \& Krall, J.F. (1977) The role of cyclic AMP in the regulation of smooth muscle contraction in the uterus. Biol. Reprod. 16, 1-17.

Krall, J.F., Schindler, A.M. \& Korenman, S.G. (1978) Myometrial protein kinase: hormone stimulated translocation and membrane binding of the soluble enzyme. Arch. Biochem. Biophys. 187, 1-11.

Lowry, O.H., Rosebrough, W.J., Farr, A.L. \& Randall, R.J. (1951) Protein measurement with the Folin phenol reagent. J. biol. Chem. 193, 265-275.

Needleman, P., Raz, A., Ferrendelli, J.A. \& Minkes, M. (1977) Application of imidazole as a selective inhibitor of thromboxane synthetase in human platelets. Proc. natn. Acad. Sci. U.S.A. 74, 17161720.
Rangel-Aldao, R., Schwartz, D. \& Rubin, C.S. (1978) Rapid assay for cyclic AMP and cyclic GMP phosphodiesterases. Analyt. Biochem. 87, 367-375.

Tai, H.H. \& Yuan, B. (1978) On the inhibitory potency of imidazole and its derivatives on thromboxane synthetase. Biochem. Biophys. Res. Commun. 80, 236-242.

Wilkinson, C.F., Hetnarski, K., Cantwell, G.P. \& DiCarlo, J.F. (1974) Structure-activity relationships in the effects of 1-alkylimidazoles on microsomal oxidation in vitro and in vivo. Biochem. Pharmacol. 23, 2377-2386.

Received 6 February 1980 